\title{
An interesting case of large colloid goiter with dyspnea
}

\author{
Jaya Prakasha Mayya, Nabin Gautam, Apar Pokharel, Bikash Pandey \\ Department of ENT, College of Medical Sciences, Bharatpur, Chitwan, Nepal.
}

\section{Correspondence}

Dr. Jaya Prakasha Mayya

Department of ENT, College of

Medical Sciences, Bharatpur,

Chitwan, Nepal.

\section{Email: \\ drmayya1@gmail.com}

DOI: http://dx.doi.org/10.3126/

jemsn.v13i4.18680

Orcid ID: orcid.org/0000-00016142-5959

Article received: Dec $1^{\text {st }} 2017$

Article accepted: Dec $12^{\text {th }} 2017$

\begin{abstract}
Benign nodular goitre is one of the most common endocrine disorder, especially in countries like Nepal where iodine deficiency is endemic. Case History: A 59 years old female presented with large thyroid swelling. Investigations showed it to be colloid goiter compressing the airway. Left hemithyroidectomy was done. Post operative period was uneventful. Discussion: Management of thyroid nodules depends upon assessment of thyroid function, fine needle aspiration cytology and imaging. Surgery is the common method of treatment.
\end{abstract}

Key words: Mucocele; rare disorder; traumatic neuroma

Citation: Mayya JP, Gautam N, Pokharel A, Pandey B. Atypical Presentation of Traumatic Neuroma: A case report. JCMS Nepal. 2017;13(4):430-2.

\section{INTRODUCTION}

Benign nodular goitre is one of the most common endocrine disorder, especially in countries like Nepal where iodine deficiency is endemic. ${ }^{1}$ Goitre is an enlargement of thyroid gland caused by compensatory hyperplasia and hypertrophy of the follicular epithelium which occurs sporadically and usually of unknown etiology. Nodular goitre presents rarely before middle age and female preponderance is established. ${ }^{2}$ Adenomatous or colloid multinodular goitre(MNG) are common, occuring in three to five percent of the general population, haemorrhage, fibrosis and calcification are found within goitres and the incidence of malignant transformation is approximates five to seven percent. ${ }^{3}$ We here present a rare case of nodular colloid goiter which presented as dyspnea.

\section{CASE DESCRIPTION}

A 59 years old female presented to our outpatient department of Otolaryngology and Head and Neck Surgery, College of Medical Sciences, Chitwan with large swelling over the anterior part of neck left sided for the past ten years. When she first noticed the swelling, it was the size of her thumb. In due course, it gradually increased in size to attain the present size. Clinical examination revealed a smooth lobulated solid to cystic mass approximately $10 \times 9 \times 8$ $\mathrm{cm}^{3}$ in size extending from just below the chin to the supra-sternal notch as seen in Figure 1.

Swelling moved with deglutition and there were no dilated vessels over the swelling. No enlarged lymph nodes were palpated. Also, the patient gave a history of shortness of breathfor5 days with hoarseness of voice.Patient was a known case of hypertension under medication.

Thyroid function test (TFT), Fine Needle Aspiration Cytology (FNAC) and Computerised Tomography (CT) were advised. Although, TFT was normal, FNAC smears showed occasional macrophages in 
background of extensive thin and few thick colloid and proteinaceous materials suggestive of colloid goiter. CT scan showed large heterogenous dense lesion with predominant non enhancing cystic component, eccentric calcifications and without enhancing solid mural nodules within in left side of neck, arising from left side of lobe-likely to be benign lesion. Significant mass effect caused by the lesion with no obvious retrosternal extension of the lesion .with small benign lesion in right thyroid lobe as seen in Figure 2.

All other haematological and biochemical profile were within the normal range. On the basis of above findings the patient was planned for surgery. A transverse neck incision two finger width above the suprasternal notch was given. The incision was subsequently deepened up to subcutaneous fat level. Skin flaps were raised in subplatysmal plane superiorly to the thyroid notch and inferiorly to the sternal notch and dissection done between strap muscle and thyroid capsule. Gentle finger dissection was used to free the goitre circumferentially, from the surrounding soft tissues, anteriorly and proceeding laterally, posteriorly and inferiorly. The dissection is facilitated by simultaneous traction. Left side of the thyroid lobe was removed as seen in Figure 3.

Patient was sent to general otorhinolaryngology ward for observation, no tracheostomy was done. There were no features of hypocalcemia postoperatively. She stayed in hospital for seven

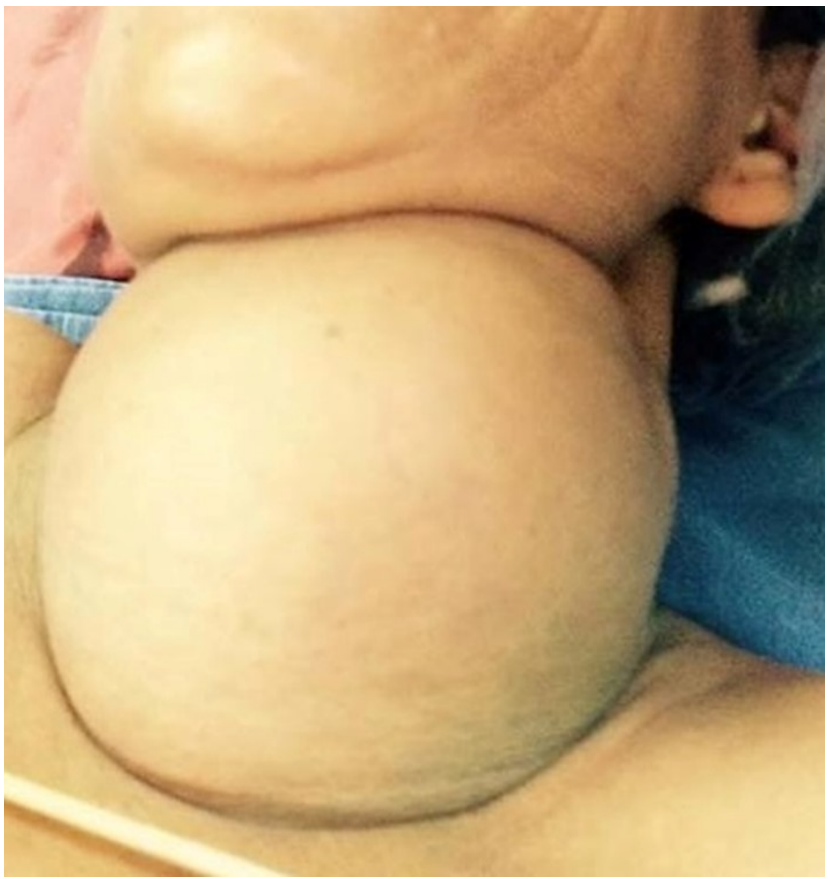

Figure 1: Large Colloid Goitre days which were uneventful. Suture removal was done on 7th post-op day and was discharged on the same day. The specimen was sent for histopathological examination that revealed colloid goiter.

\section{DISCUSSION}

Management of thyroid nodules depends upon assessment of thyroid function, fine needle aspiration cytology and imaging. ${ }^{5}$ Surgery is the common method of treatment whenever possible , while other option includes radioactive iodine. ${ }^{4}$

Surgery for thyroid is done for exclusion of thyroid carcinoma or if there is benign thyroid disease which give rise to dysphagia or stridor following compression of the oesophagus or trachea and for the cosmetic purposes. ${ }^{6}$

In 1866, Samuel Gross wrote that thyroid surgery should be considered as horrible butchery and that no sensible and honest surgeon would be engaged in its practice. Kocher received novel prize for his work in thyroid surgery where with his accurate technique he reduced the bleeding during thyroid surgery and reported $0.2 \%$ hemorrhage rate in more than 5000 surgeries he performed.

In our case we did left sided hemithyroidectomy, and the patient is not having any symptoms which were prevalent before surgery.

\section{CONCLUSION}

The majority of thyroid nodule are benign as in this

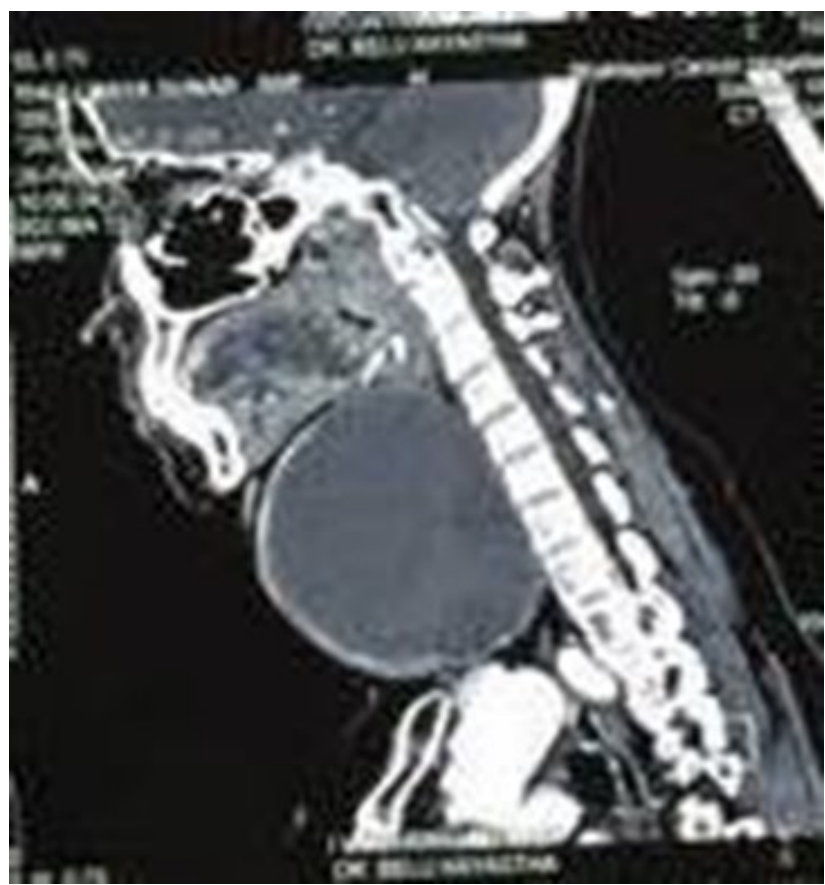

Figure 2: CT scan Neck showing large colloid goiter 


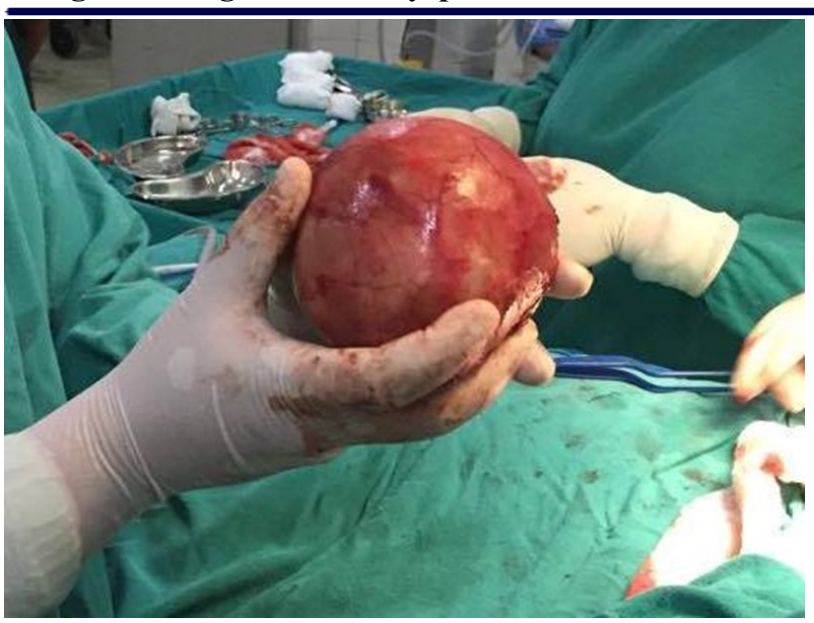

\section{Figure 3: Removal of Goitre}

case. However if the thyroid nodule is very big, it produces compressive symptoms like dysphagia, stridor. Surgery is the effective treatment.

\section{REFERENCES}

1. Matovinovic J. Endemic goiter and cretinism at the dawn of the third millennium. Annu Rev Nutr. 1983;3:341-412. https://doi.org/10.1146/annurev.nu.03.070183.002013.

PMID: 6196041.

2. Sharma, B. A case of Colloidal Nodular Goiter, Indian Journal of Research in Homoeopathy 2011;5:40-6.

3. Clarke S. The thyroid gland : function tests and imaging, Scott-Brown's volume 1-A,seventh edition, 2008, Chapter 27, pg-327-337. https://doi.org/10.1201/b15118-34.

4. Bonnema SJ, Fast S, Hegedüs L. The role of radioiodine therapy in benign nodular goitre. Best Pract Res ClinEndocrinolMetab. 2014;619-31. https:// doi.org/10.1016/j.beem.2014.02.001. PMid:25047210

5. Moulick ND. Multinodular Thyroid Disease. Medicine Update 2008 Vol. 18,Chapter 83, p-615-27

6. Welbourn RB. The history of endocrine surgery. New York: Praeger, 1990;2:19-82.

7. Albott JH. A biographical history of medicine: excerts and essays on the men and their work. New York :Grune Stratton, 1970;1012-1014:1044-6 